\title{
STRESS INTERACTION BETWEEN THRUST FAULTS ALONG THE SW HELLENIC ARC (GREECE)
}

\author{
Messini A. D. ${ }^{1}$, Papadimitriou E. E. ${ }^{1}$, Karakostas V. G. ${ }^{1}$, and Baskoutas I. ${ }^{2}$ \\ ${ }^{1}$ Geophysics Department, University of Thessaloniki, GR54124 Thessaloniki, Greece, \\ anna.messini@gmail.com,ritsa@geo.auth.gr,vkarak@geo.auth.gr \\ ${ }^{2}$ Geodynamic Institute, National Observatory of Athens, GR11810 Athens, Greece
}

\begin{abstract}
The occurrence of strong earthquakes $(M \geq 6.3)$ and the evolution of the stress field along the southwestern part of the Hellenic arc since 1959 are examined by the calculation of Coulomb stress changes. The study area is characterized by low angle thrust faults and high seismicity as being part of the subduction interface. Coulomb stress changes were calculated assuming that earthquakes can be modeled as static dislocations in an elastic half-space, considering the co-seismic slip during strong events and the slow tectonic stress build-up along major fault segments due to the movements of the tectonic plates. The ruptures are modeled taking into account the strike, dip, and rake appropriate to each event examined. It is evaluated whether the stress changes brought a given earthquake closer to, or farther away from, failure. It was found that the majority of the events (strong and smaller) are located in stress enhanced areas.
\end{abstract}

Key words: Coulomb stress, thrust faulting, interaction.

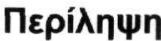

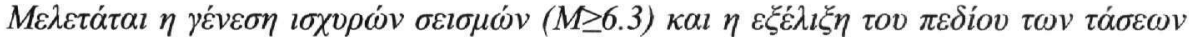

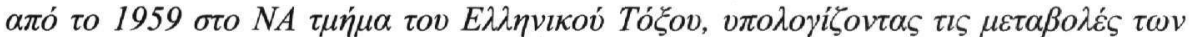

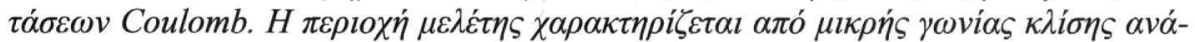

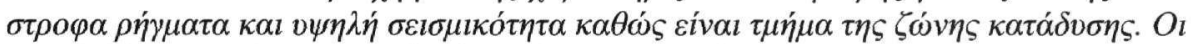

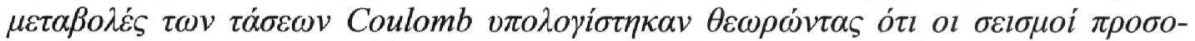

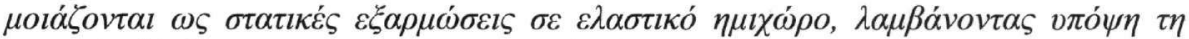

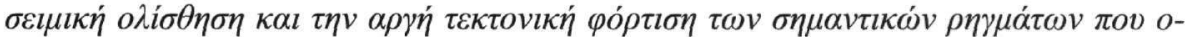

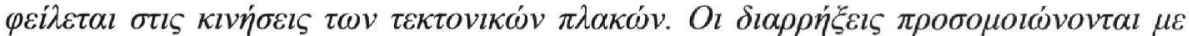

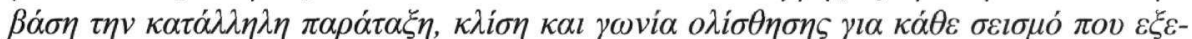

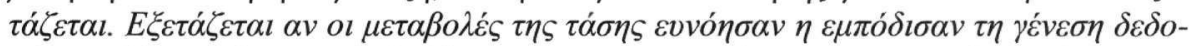

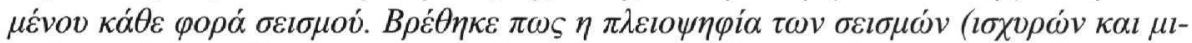

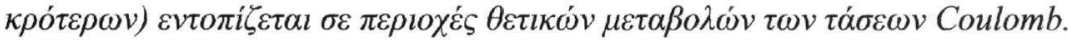

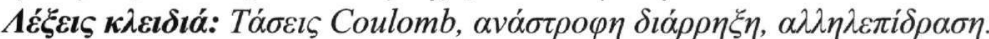

\section{Introduction}

The most prominent feature of the broader Aegean region (Fig. 1) is the Hellenic arc and the associated Benioff zone, formed by the subduction of the Eastern Mediterranean oceanic plate beneath 
the Aegean micro-plate (Papazachos and Comninakis 1970). Reliable fault plane solutions allowed a better understanding of the active tectonics in the study area since 1960. Thrust faulting dominates along the arc, with a NE-SW direction of the axis of maximum compression, laterally bounded by the dextral Cephalonia Transform Fault (CTF) to the west and Rhodes sinistral fault to the east (Papazachos 1961). Govers and Wortel (2005) refer to these strike slip faults as Subduction-Transform Edge Propagator (STEP) faults, and suggest that they are formed at the termination of subduction trenches and are a geometric consequence that allows subduction to continue.

The Hellenic subduction zone is characterized by high seismicity along the arc. Historical information evidences the occurrence of large events $\left(M_{s} \geq 7.5\right)$ at the southwestern part of the arc around the island of Crete, such as the 62 A.D., 251, 1494, and 1810 events of $M 7.5$, the 1856 event with M7.7, and the 365 A.D. event of M 8.3 (Papazachos and Papazachou 2003). Severe damage both in the natural and constructed environment and loss of life were the consequences of these events occurrence. This high seismic activity necessitates seismic hazard assessment in the study area that is attempted here by resolving the evolution of the stress field and inspecting possible triggering of the next events in a sequence of events.

Earthquakes in sequence generally are not independent but each one is affected both by tectonic loading and stress changes caused by coseismic slip in prior events (Scholz 1990). There is a plethora of studies exploring the phenomenon of triggering of subsequent earthquakes by static or dynamic stress changes during the past decade (see reviews by Harris 1998, King and Cocco 2001). Many researchers focused their studies on strike slip faults such as the San Andreas, North Anatolian and Eastern California Shear zone since the pattern of stress transfer does not vary greatly with depth. The majority of thrust earthquakes on the other hand occur in subduction zones offshore, where seismic and geodetic coverage is often poor. Despite these limitations, previews studies of subduction earthquakes (Dmowska et al. 1988, Lin and Stein 2004, among others) pointed out the important role of stress interaction in such tectonic environments.

In this study, we explore the Coulomb stress changes $(\triangle \mathrm{CFF})$ associated with strong earthquakes $(\mathrm{M} \geq 6.3)$ and the evolution of the stress field along the southwestern part of the Hellenic arc since 1959, when more reliable information on earthquake source parameters is available. These earthquakes are included in the stress evolution model along with the long-term tectonic loading on the major thrust faults of the area. We aim to examine if the coseismic and cumulative changes in stress can explain the spatial and temporal occurrence patterns of past strong earthquakes.

\section{Method}

Static stress changes associated with strong and large earthquakes influence the space-time pattern of the following seismicity (Deng and Sykes 1997, Harris 1998 and references therein). The advantage of using stress changes is that often absolute values of stress are not known, but stress change values can be calculated from information about the geometry and slip of an earthquake rupture. The method introduced by Deng and Sykes (1997) is used in the present study to calculate stress changes associated to all of the events examined. According to this method, stress is considered a tensor quantity that varies in time and space, with the Earth approximated as homogenous elastic half space. Cumulative changes in stress are assumed to arise from tectonic loading generated by the plate motions and displacements on faults associated to strong earthquakes. Interseismic stress accumulation is modeled by introducing "virtual negative displacements" along major faults in the entire region under study, using the best available information on long term slip rates. This virtual dislocation has the same size and orientation as the fault segment in question, but with the opposite sense of slip. The value of slip on the virtual dislocation is incremented in time according to the long-term slip rate along the fault. The fault segment is considered to slip constantly from the bottom of the seismogenic layer to infinite depth. Hence tectonically induced stress builds up in the vicinity of faults during the interseismic periods. Stress buildup is released wholly or in part during the next strong earthquake, with real displacements on given faults that 
are considered positive in the model. Changes in stress associated with strong earthquakes are modeled by introducing certain co-seismic displacements on ruptured fault segments in elastic half-space and adding the changes in the components of the stress tensor together as they occur in time.

Earthquakes occur when stress exceeds the fault strength. The closeness to failure is quantified by using the change in Coulomb failure function ( $\triangle \mathrm{CFF}$ ) (modified from Scholz 1990). It depends on both changes in shear stress, $\Delta \tau$, and normal stress, $\Delta \sigma$ :

\section{Equation 1}

$\Delta C F F=\Delta \tau+\mu^{\prime} \Delta \sigma$

Here $\mu^{\prime}$ is the apparent coefficient of friction and its value was chosen to be equal to 0.4 and considered sufficient throughout the calculations (King et al. 1994, Lin and Stein 2004). Bird and Kagan (2004) use a value of 49GPa for subduction zones in an effort to encompass the presence of both crust and mantle rocks, which is also adopted in the present study. The change in shear stress, $\Delta \tau$, is positive for increasing shear stress in the direction of relative slip on the observing fault while $\Delta \sigma$ is positive for increasing tensional normal stress. When compressional normal stress on a fault plane decreases, the static friction across the fault plane also decreases. Both positive $\Delta \tau$ and $\Delta \sigma$ move a fault toward failure while negative values of $\Delta \tau$ and $\Delta \sigma$ move it away from failure. Therefore, a positive value of $\Delta \mathrm{CFF}$ for a particular fault denotes an increased likelihood that it will rupture in an earthquake.

\section{Fault plane solutions and major faults}

Reliable fault plane solutions (FPS) of the earthquakes that occurred along the southwestern Hellenic arc were collected from previous publications and CMT Harvard solutions (Table 1) and are shown as lower hemisphere equal area projections in Figure 1, which evidences the dominancy of thrust faulting in the study area. Papazachos et al. (2001) used seismological and geological data in order to determine the properties of the faults where the known major $(M \geq 6.0)$ shallow (depth $<40$ $\mathrm{km}$ ) earthquakes have occurred since 480 B.C. (shown by their code names in Fig. 1). The belt of low angle thrust faults along the Hellenic arc, strikes from NW to SE parallel to the coastline and dips to the NE following the Benioff zone. Shallow dipping mechanisms are characteristic of subduction zones and are related to the motion of the overriding lithosphere. The axis of maximum compression along the arc has a NE-SW direction (Fig. 1). Information on reliable fault plane solutions and topography as well as the above mentioned information was used in the present study in order to define the location and geometry of the faults associated with each event (indicated by the earthquake occurrence year in Figure. 1) as well as the faults across which the tectonic loading is accommodated (IFS and CFS in Fig. 1).

Table 1 - Information on the available fault plane solutions for events of $M \geq 4.5$ that occurred in the study area since 1959. 1. Papazachos and Papazachou (1997), 2. McKenzie (1972), 3. Kiratzi and Langston (1989), 4. McKenzie (1978), 5. Papadimitriou (1993), 6. Taymaz et al. (1990), 7. Benetatos et al. (2004), 8. CMT Harvard solutions, 9. Louvari (2000)

\begin{tabular}{|c|c|c|c|c|c|c|c|c|c|c|}
\hline \multicolumn{3}{|c|}{ Origin } & \multicolumn{2}{|c|}{ Epicenter } & \multirow{2}{*}{$\begin{array}{c}\text { Depth } \\
\text { km }\end{array}$} & \multirow[b]{2}{*}{$\mathbf{M}$} & \multicolumn{3}{|c|}{ Mechanism (Deg) } & \multirow[t]{2}{*}{ Ref } \\
\hline Year & Date & Time & Lat & Lon & & & strike & Dip & Rake & \\
\hline 1959 & $05 / 14$ & $06: 36: 56$ & 35.00 & 24.72 & 39 & 6.3 & 309 & 35 & 99 & 1 \\
\hline 1965 & $04 / 09$ & $23: 57: 02$ & 35.13 & 24.31 & 39 & 6.1 & 301 & 18 & 98 & 1 \\
\hline 1969 & $06 / 12$ & $15: 13: 31$ & 34.40 & 25.00 & 19 & 6.1 & 294 & 29 & 105 & 2 \\
\hline 1972 & $05 / 04$ & $21: 39: 57$ & 35.10 & 23.60 & 40 & 6.5 & 309 & 18 & 89 & 3 \\
\hline 1973 & $01 / 05$ & $05: 49: 18$ & 35.72 & 21.73 & 42 & 5.6 & 306 & 30 & 82 & 4 \\
\hline 1973 & $11 / 29$ & $10: 57: 44$ & 35.18 & 23.75 & 22 & 6.0 & 283 & 38 & 97 & 5 \\
\hline
\end{tabular}




\begin{tabular}{|l|l|l|l|l|l|l|l|l|l|l|}
\hline 1977 & $08 / 18$ & $09: 27: 41$ & 35.32 & 23.43 & 13 & 5.6 & 265 & 13 & 62 & 6 \\
\hline 1977 & $09 / 11$ & $23: 19: 19$ & 34.90 & 23.00 & 16 & 6.3 & 295 & 40 & 95 & 5 \\
\hline 1979 & $05 / 15$ & $06: 59: 23$ & 34.54 & 24.50 & 35 & 5.7 & 253 & 17 & 65 & 6 \\
\hline 1983 & $03 / 19$ & $21: 41: 39$ & 34.68 & 25.33 & 65 & 5.6 & 358 & 39 & 131 & 8 \\
\hline 1984 & $06 / 21$ & $10: 43: 46$ & 35.40 & 23.30 & 40 & 6.2 & 322 & 16 & 114 & 5 \\
\hline 1985 & $04 / 21$ & $08: 49: 42$ & 35.63 & 22.01 & 25 & 5.2 & 149 & 50 & 78 & 7 \\
\hline 1995 & $12 / 07$ & $18: 00: 53$ & 34.73 & 23.94 & 15 & 5.6 & 319 & 6 & 123 & 8 \\
\hline 1995 & $12 / 10$ & $03: 27: 50$ & 34.76 & 23.98 & 17 & 5.3 & 289 & 22 & 75 & 8 \\
\hline 1997 & $10 / 13$ & $13: 39: 39$ & 36.44 & 22.16 & 32 & 6.4 & 322 & 19 & 108 & 9 \\
\hline 1997 & $11 / 05$ & $12: 22: 53$ & 34.90 & 24.00 & 22 & 5.5 & 309 & 6 & 108 & 9 \\
\hline 1999 & $04 / 17$ & $08: 17: 58$ & 36.03 & 21.59 & 27 & 5.3 & 172 & 59 & 95 & 7 \\
\hline 2000 & $02 / 22$ & $11: 55: 31$ & 34.95 & 25.38 & 20 & 5.0 & 92 & 71 & 68 & 7 \\
\hline 2000 & $05 / 24$ & $10: 01: 44$ & 35.80 & 21.95 & 18 & 5.5 & 111 & 80 & 63 & 7 \\
\hline 2004 & $03 / 28$ & $14: 54: 48$ & 35.57 & 22.99 & 55 & 4.7 & 310 & 31 & 97 & 8 \\
\hline 2004 & $11 / 04$ & $06: 22: 40$ & 35.71 & 23.03 & 85 & 5.2 & 186 & 48 & 58 & 8 \\
\hline
\end{tabular}

\section{Rupture models}

Earthquakes of $M \geq 6.3$ that occurred since 1959 in the study area are included in the stress evolutionary model. Starting year and cutoff magnitude where selected based on the fact that reliable fault plane solutions derived by waveform modeling exist for earthquakes of $M \geq 6.3$ since 1959 in the area of Greece.

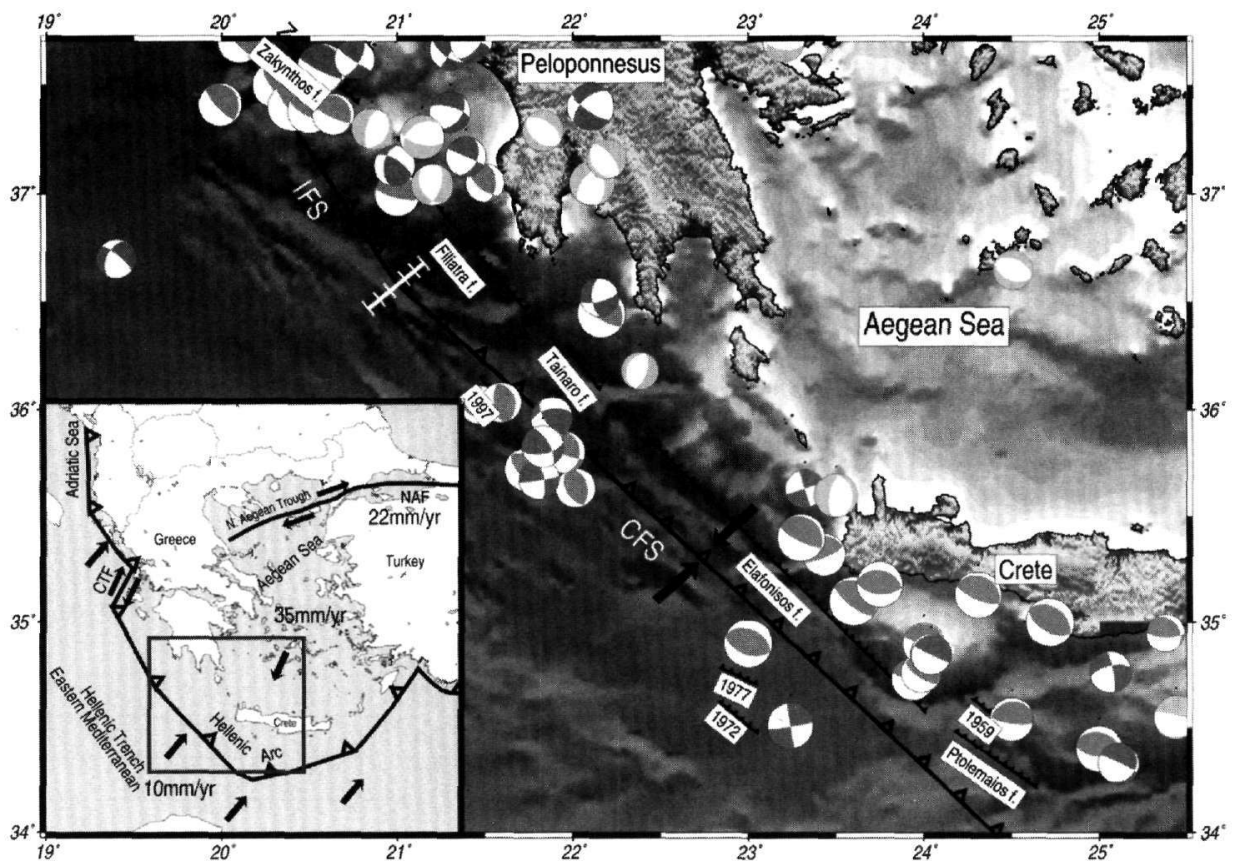

Figure 1 - Major faults along with the focal mechanisms of strong and moderate earthquakes in the studied area. Inset: Seismotectonic properties of the Aegean and surrounding regions. (IFS: Ionian Fault Segment; CFS: Crete Fault Segment; CTF: Cephalonia Transform Fault; NAF: North Anatolian Fault). Arrows indicate relative plate motions (After Papazachos 1999 and McClusky et al. 2000)

The rupture zones are simplified and approximated by rectangular planes. Three parameters essential to the model application are fault length, width, and average displacement. Therefore, the cal- 
culation of the main rupture dimensions and the average coseismic slip are necessary. The distribution of slip is non-uniform along a fault, but detailed source models are not necessary when calculating the far field stress distributions (King and Cocco 2001). Thus, uniform average slip is adequate for $\triangle \mathrm{CFF}$ determination, calculated using a scaling law by Papazachos et al. (2004) for dipslip subduction faulting:

\section{Equation 2}

$\log u=0.64 M-2.56$

Since all faults are offshore and geological data are not available to determine fault length, it was determined by the equation (3) (Papazachos et al. 2004) valid for subduction earthquakes:

\section{Equation 3}

$\log L=0.55 M-2.19$

The rupture zones of subduction thrust earthquakes do not propagate all the way to the surface at the trench and their down-dip termination occurs at depths that vary between 40 and $60 \mathrm{~km}$ (Scholz 1998). For the Hellenic subduction zone rupture terminates at 35 to $50 \mathrm{~km}$ (Papazachos et al. 2000, Laigle et al. 2004, Papadimitriou and Karakostas 2005). For an arc with low seismic coupling, such as the Hellenic arc, earthquakes tend to have small rupture zones and the zones of high moment release are small isolated patches on the subduction interface (Scholz 1990). In an effort to distinguish large and small earthquakes, Scholz (1982) stated that the large ones propagate throughout the brittle crust and they can be represented as a rectangular rupture with one edge at the free surface. Small earthquakes on the other hand can be represented as circular sources in an elastic medium. These observations led us to conclude that a constraint had to be set concerning fault width.

The ability of a thrust earthquake to promote failure along strike depends on its length/width (L/w) ratio (Lin and Stein 2004). Large ( $M>7)$ thrust earthquakes become longer along strike because their down-dip extent is limited by the finite depth of the brittle elastic crust, thus $\mathrm{L} / \mathrm{w}>1$. All subduction earthquakes in our sample with magnitudes $6.3 \leq \mathrm{M} \leq 6.6$ are considered small earthquakes, thus, we set the constraint $\mathrm{L} / \mathrm{w} \approx 1$. The earthquake source parameters for applying the evolutionary model are given in Table 2.

Table 2 - Source parameters of $M \geq 6.3$ earthquakes that are included in the stress evolutionary model [1. Papazachos and Papazachou (1997), 2. Kiratzi and Langston (1989), 3. Papadimitriou (1993), 4. Louvari (2000)]

\begin{tabular}{|c|c|c|c|c|c|c|c|c|c|c|c|}
\hline Date & $\begin{array}{c}\text { Lat } \\
(\mathrm{N})\end{array}$ & $\begin{array}{c}\text { Long } \\
(\mathrm{E})\end{array}$ & $\begin{array}{c}\text { Depth } \\
(\mathrm{km})\end{array}$ & $\begin{array}{c}\mathbf{L} \\
(\mathrm{km})\end{array}$ & $\begin{array}{c}\mathbf{W} \\
(\mathrm{km})\end{array}$ & $\mathbf{M}$ & $\begin{array}{c}\mathbf{u} \\
(\mathrm{cm})\end{array}$ & Strike & Dip & Rake & Ref \\
\hline $14 / 05 / 59$ & 35.00 & 24.72 & 39 & 19 & 12 & 6.3 & 17.8 & 309 & 35 & 99 & 1 \\
\hline $04 / 05 / 72$ & 35.10 & 23.60 & 40 & 27 & 26 & 6.5 & 24.0 & 309 & 25 & 89 & 2 \\
\hline $11 / 09 / 77$ & 34.90 & 23.00 & 16 & 19 & 12 & 6.3 & 17.8 & 295 & 40 & 95 & 3 \\
\hline $13 / 10 / 97$ & 36.45 & 22.16 & 32 & 21 & 21 & 6.4 & 19.9 & 322 & 25 & 108 & 4 \\
\hline
\end{tabular}

\section{Geometry and long term slip rate constraints on major faults}

In order to incorporate tectonic loading at the subduction front in our stress evolution model we introduce two major thrust fault segments, along the subduction interface, where we consider the tectonic loading. These are hereafter mentioned as the Ionian Fault Segment (IFS: W part of the arc) and the Crete Fault Segment (CFS: SW part of the arc) and are shown in Figure 1. Assuming that all thrust earthquakes along the arc occur on the plate interface, the distribution of moderate earthquakes $(M \geq 4.5)$ and their fault plane solutions are used along with local topography in order 
to define the geometry of these fault segments. Information from recent publications on the geometry of the subduction zone was also taken into account. Strike and location was constrained by the distribution of $\mathrm{M} \geq 4.5$ earthquakes and ocean bottom topography. A dip of $25^{\circ}$ was assigned to the IFS since most of the fault plane solutions of earthquakes in that area show fault planes with a dip ranging from $17^{\circ}$ to $25^{\circ}$. The CFS is shallower than the IFS (Papazachos et al. 2000, Laigle et al. 2004, Meier et al. 2004, Papadimitriou and Karakostas 2005), and its dip is considered equal to $20^{\circ}$ (Papadimitriou and Karakostas, 2005), and the faulting type along the plate interface as pure thrust (rake: $90^{\circ}$ ) on both fault segments (Table 3).

The available information on the kinematics of the Hellenic is used for the definition of the longterm slip constraint. Many models have been proposed concerning the number of plates involved in the formation of the subduction zone and the orientation and proportion of the relative movements (e.g., Taymaz et al. 1991). Seismological (fault plane solutions, seismic moment release rates) and geodetic (Global Positioning System-GPS, Satellite Laser Ranging-SLR) data have been used by various researchers in order to determine the direction and the velocity of these movements.

Reference is given briefly in several previous works dealing with the kinematics in this part of the Hellenic Arc, since there is a plethora of published studies and geodetic data that we cannot ignore. We focus on geodetic results with a reference frame fixed on Eurasia.

Kahle et al. (1995) obtained a SW-oriented movement of SW Greece with an average velocity of $30 \mathrm{~mm} / \mathrm{yr}$, the rates being increasing from the area south of the central Ionian Islands to the southwestern tip of Peloponnesus reaching 40mm/yr. Le Pichon et al. (1995) suggested that the Aegean moves with a velocity of about $38 \mathrm{~mm} / \mathrm{yr}$ with respect to Africa. Papazachos and Kiratzi (1996) estimated $13 \mathrm{~mm} / \mathrm{yr}$ crustal shortening along the outer part of the Hellenic arc with the use of seismological data. Davies et al. (1997) using GPS measurements observed that trench ward velocity increases towards the Western Hellenic arc from $30 \mathrm{~mm} / \mathrm{yr}$ in NE Aegean to $50 \mathrm{~mm} / \mathrm{yr}$ in SW Peloponnesus. Reilinger et al. (1997) based on GPS measurements of crustal motions for the period 1988-1994 and available SLR data, and Lundgren et al. (1998) along with additional SLR data obtained a convergence velocity at 33 to $36 \mathrm{~mm} / \mathrm{yr}$ in the southern part of the arc and a velocity of $35 \mathrm{~mm} / \mathrm{yr}$ in the western Hellenic arc. Papazachos (1999) estimated trench ward velocity equal to $30-35 \mathrm{~mm} / \mathrm{yr}$ using seismological and geodetic data.

Table 3 - Information on the major fault segments introduced in the stress evolutionary model to incorporate tectonic loading

\begin{tabular}{|l|l|c|c|c|c|c|c|c|}
\hline No & \multicolumn{1}{|c|}{ Fault name } & \multicolumn{2}{|c|}{$\begin{array}{c}\text { Center } \\
\text { Lat }\end{array}$} & $\begin{array}{c}\text { Strike } \\
\text { Leng }\end{array}$ & $\begin{array}{c}\text { Dip } \\
\text { deg }\end{array}$ & $\begin{array}{c}\text { Rake } \\
\text { deg }\end{array}$ & $\begin{array}{c}\text { L } \\
\text { km }\end{array}$ & $\begin{array}{c}\text { Slip } \\
\text { mm yr }^{-1}\end{array}$ \\
\hline 1. & $\begin{array}{l}\text { Ionian Fault Segment } \\
\text { (IFS) }\end{array}$ & 37.20 & 20.49 & 325 & 25 & 90 & 167 & 13 \\
\hline 2. & $\begin{array}{l}\text { Crete Fault Segment } \\
\text { (CFS) }\end{array}$ & 35.29 & 22.7 & 312 & 20 & 90 & 410 & 4.5 \\
\hline
\end{tabular}

Cocard et al. (1999) based on GPS measurements and obtained a maximum rate along the SW part of Peloponnesus of the order of $40 \mathrm{~mm} / \mathrm{yr}$ decreasing to $35 \mathrm{~mm} / \mathrm{yr}$ on the island of Crete. McClusky et al. (2000) presented GPS measurements for the period 1988-1997 and concluded that the largest relative motions across plate boundaries occur along the Hellenic Trench at $35 \pm 1 \mathrm{~mm} / \mathrm{yr}$ with respect to Eurasia and Africa moves to the north at $5.4 \pm 1 \mathrm{~mm} / \mathrm{yr}$ with respect to Eurasia. Kreemer and Chamot-Rooke (2004) calculated a continuous velocity and strain rate field using published GPS data and suggested that the Aegean block moves consistently at 33 to $34 \mathrm{~mm} / \mathrm{yr}$ towards the $\mathrm{SW}$ in an Africa-Eurasia reference frame.

It is well recognized that only part of the total amount of tectonic loading due to the plate convergence is released seismically. Some sections of plate boundaries are deficient in their moment release as compared with plate tectonic estimates. The contribution of seismicity to the convergence 
of the Aegean and Arabian plates has been found to be small indicating that this subduction is occurring largely aseismically. The western part of the arc seems to have a higher seismic coupling coefficient than the southern part of the arc. The first authors to recognize the aseismic nature of the southern part of the Aegean were Galanopoulos (1967) and Ergin (1966). Jackson and McKenzie (1988) suggest that only $10 \%$ of the upper crustal deformation is taken up seismically in the southwestern part of the arc and 30-35\% in the western part. Papazachos and Papazachou (2003), pointed out that $30 \%$ of total convergence rate at $45 \mathrm{~mm} / \mathrm{yr}$ is seismic, resulting in $13.5 \mathrm{~mm} / \mathrm{yr}$ of seismic slip. Papazachos and Kiratzi (1996) computed a mean deformation velocity, in terms of seismic energy release, of $12 \mathrm{~mm} / \mathrm{yr}$ in the western part of the arc. Papadimitriou and Karakostas (2005) constrained seismic coupling to $10 \%$ in the SW part of the arc. Considering these observations we assume seismic slip to be $13 \mathrm{~mm} / \mathrm{yr}$ in the western part of the arc and $4.5 \mathrm{~mm} / \mathrm{yr}$ in the southwestern part of the arc.

\section{Coseismic stress changes}

In Figure 2 the coseismic stress changes associated with four strong events occurred during 19592005 are shown. In each part of the figure we show thrust fault plane solutions of all the subsequent earthquakes and plot the ones with differences in strike, dip and rake up to $30^{\circ}$ using black color, taking into account the $20^{\circ}$ error in the determination of focal mechanisms. The rest of the subsequent thrust fault plane solutions are shown in light gray and the focal mechanism of the next strong event is shown in dark gray. Dark gray regions denote negative changes in CFF and inferred decreased likelihood of fault rupture (stress shadows). Light gray regions represent positive $\Delta \mathrm{CFF}$ and increased likelihood of fault rupture (stress bright zones). It must be mentioned that stress is a tensorial quantity so it depends not only on the source fault geometry and slip, but also on the geometry and rake of the target (receiver) faults. Thus shadow zones and bright zones must be viewed in the context of specific styles of fault slip, i.e., strike, dip, and rake.

Coulomb stress changes are calculated according to the geometry of the target fault, which is the fault of the subsequent strong earthquake in our sample, and at the appropriate depth. For thrust faulting the stress change is depth-dependent (Lin and Stein 2004) and thus the down-dip geometry of the source fault and the depth of receiver faults become essential to Coulomb analysis. Following King et al. (1994) who found that seismic slip peaks at mid-depths in the seismogenic zone we evaluated the mid-depth by studying the depth distribution of all moderate thrust earthquakes of our data set (Table 1). In the SW part of the arc focal depths of thrust events range from 3 to $40 \mathrm{~km}$, thus sampling depth was chosen to $20 \mathrm{~km}$.

Considering this, the coseismic stress changes associated with the 14 May 1959 ( $M$ 6.3) event are calculated according to the faulting type of the 1972 earthquake (Fig. 2A). One subsequent event with similar fault plane solution was brought closer to failure (April 1965, M 6.1) and two events $(1969,1972)$ were not inhibited. The coseismic stress changes associated with the earthquake on 4 May 1972 (M 6.5) are added to the previous ones and calculated according to the faulting of the third earthquake in 1977 (Fig. 2B). All subsequent thrust earthquakes with similar to the target fault focal mechanisms located around the 1972 epicenter, one of them being the next strong earthquake in our sample (September 1977, M 6.3), are enhanced. The August 1977 event having a different orientation than the target fault lies in the borders between stress shadow and stress bright zone and the January 1973 event is also not inhibited. In Figure 2C the coseismic stress changes associated with the earthquake of 11 September 1977 (M 6.3) are added to the stress changes associated to the previous events and resolved on the fault connected with the fourth strong earthquake in 1997. This earthquake was not inhibited by the accumulated coseismic stress changes, along with four other events $(1983,1985$, and two in 1995), while two of the subsequent earthquakes were enhanced (1979 and 1984). Figure 2D shows the coseismic stress changes associated with all four strong shocks computed according to the faulting type of the CFS. Three subsequent earthquakes (1997 and two in 2004) are located in stress enhanced areas, two more are not inhibited to fail (both in 2000), while one event lies in a stress shadow (1999). 


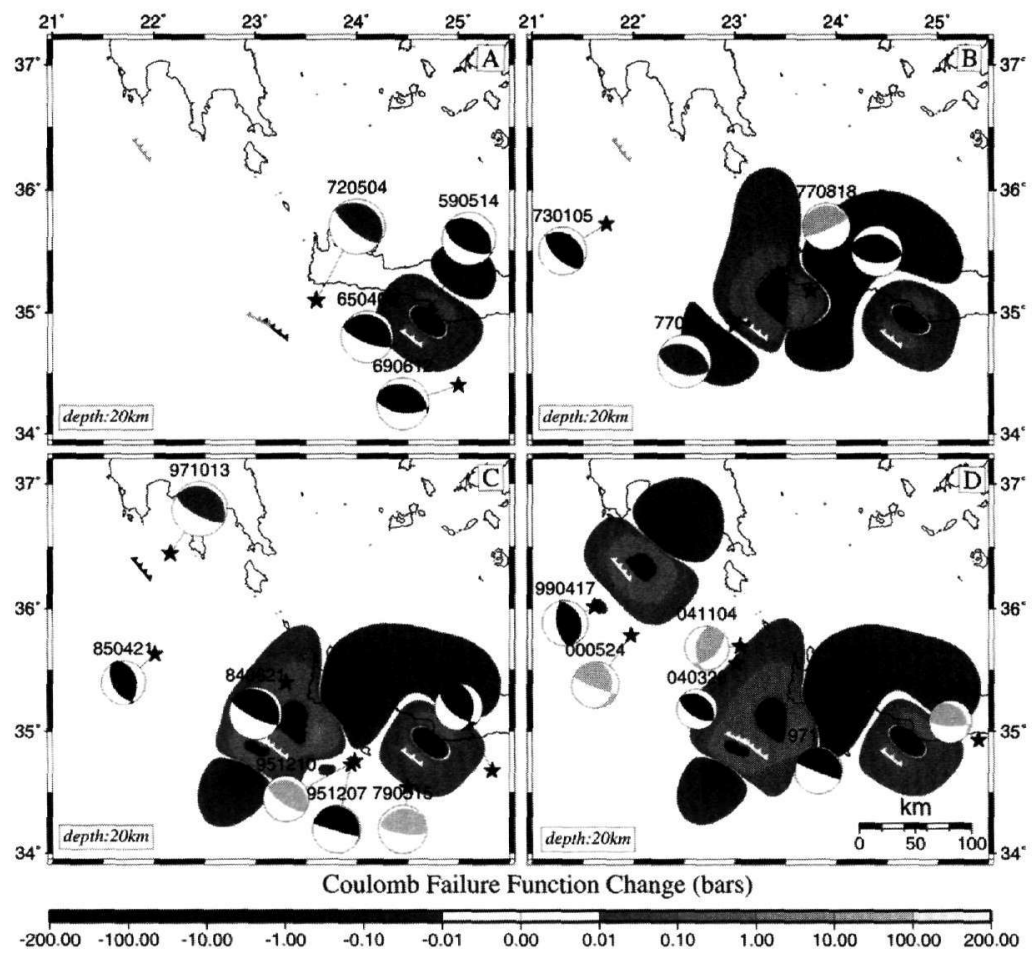

Figure 2 - Coseismic stress changes associated with the occurrence of four strong earthquakes in SW Hellenic arc since 1959. Stress changes are denoted by the scale at the bottom (in bars) and are calculated for thrust faults at $20 \mathrm{~km}$. The stress pattern is calculated according to the fault plane solution of the next strong event. Fault plane solutions are shown as lower-hemisphere equal-area projections and the occurrence date (Year/Month/Day) is given at the top of each focal sphere. Black focal spheres are similar to the fault plane solution of the target event (up to $30^{\circ}$ difference in strike, dip and rake), whose focal sphere is in dark gray and its fault is black while the rest thrust fault plane solutions are light gray. Fault traces that have already ruptured are in white and the rest are ingray. Stars denote epicentres of earthquakes and are connected with a thin line to the FPS of the event. (A) Co-seismic Coulomb stress changes associated with the 1959 event imparted on the 1972 rupture zone. (B) Co-seismic Coulomb stress changes associated with the 1959 and 1972 events imparted on the 1977 rupture. (C) Co-seismic Coulomb stress changes associated with the 1959, 1972 and 1977 events imparted on the 1997 rupture. (D) Coulomb stress changes associated with the four strong events imparted on the SW part of the arc

\section{Stress evolutionary model}

The history of cumulative stress changes, due to both coseismic slip during the strong earthquakes and the tectonic loading on the major faults in the study area, is examined in an attempt to explore the spatial and temporal occurrence patterns of such earthquakes. To this effect, we examine the evolution of the stress field since 1959 and assume stress changes to be zero before that time. We will show that according to the stress evolutionary model, all the larger earthquakes subsequently occurred in bright zones, not in shadow ones. To do this, we only show mechanisms of shocks of similar type of faulting for which the stress calculations are performed (Fig. 3). Most of the moderate thrust shocks with similar fault plane solution (black focal spheres), for which the stress calculations are performed, were located in stress-enhanced zones. In each snapshot, $\triangle \mathrm{CFF}$ is calculated for a preferred focal mechanism, the one of the next event whose triggering is inspected. 
Each snapshot shows the state of the stress field just before the occurrence of the next earthquake included in the stress evolutionary model resolved on its fault plane.

The coseismic stress changes associated with the 1959 event are calculated according to its fault plane solution at a depth of $20 \mathrm{~km}$ (Fig. 3A). The accumulated stress changes just before the May 1972 thrust event resolved on its fault plane are shown in Figure 3B. A broad bright zone encompasses the area due to tectonic loading on the CFS. Both the epicentre of this earthquake and the epicentre of a preceding event (April 1965 M 6.1) lie in a stress enhanced area, while the location of one event (July 1969 M 6.1) is in the borders between stress shadow and stress bright zones. In Figure 3C the accumulated stress changes just before the January 1977 event are calculated according to its fault plane solution are shown. The bright zone is more pronounced and encompasses all the thrust earthquakes that occurred during 1972-1977. In Figure 3D the accumulated stress changes just before the October 1997 event are calculated. The model successfully explains the locations of all the thrust earthquakes that occurred in the time period 1977-1997. Figure 3E shows stress accumulated on the CFS in 46 years (1959-2005) and the coseismic stress changes of the strong events included in the evolutionary model. The pattern remains the same though it is more enhanced. All thrust earthquakes that occurred after 1997 up to 2005 are located in stress enhanced regions.

\section{Discussion}

We explore the Coulomb stress changes $(\triangle \mathrm{CFF})$ associated with strong earthquakes $(\mathrm{M} \geq 6.3)$ that occurred along the southwestern part of the Hellenic arc since 1959. The investigation could not be extended to the rest of the Hellenic arc since no strong earthquakes occurred in the SE part of the arc during the study period. We applied a stress evolutionary model in the study area for the period 1959-2005 in order to examine if the history of coseismic and cumulative changes in stress can explain the spatial and temporal occurrence of strong $(\mathrm{M} \geq 6.3)$ and smaller earthquakes.

When considering coseismic stress changes our results suggest that thrust earthquakes interact around CFS, since when a strong shock occurs it changes the conditions for failure in its vicinity. The strong event of September 1977, as well as several of the subsequent earthquakes with similar fault plane solutions, are enhanced by the May 1972 shock.

Stress loading on the Ionian and Crete fault segments modulates the stress acting on nearby thrust faults. When considering the accumulated stress changes our analysis is successful in explaining the location of moderate to strong earthquakes in the study area. It has been shown that all events are located in areas of positive $\triangle \mathrm{CFF}$ except the June $1969(\mathrm{M}=6.1)$ event near Crete.

It is well accepted that earthquakes occur in stress enhanced areas The inability of any Coulomb stress model to be consistent with this observation is attributed to the following factors: uncertainties both in location and depth constraints, details on coseismic slip, geodetic analyses for the long term slip rate along the fault and sensitivity of the stress pattern of thrust events to small changes of fault dip and focal depth. In addition, one should consider that subduction earthquakes are patches on the subducting interface rather than ruptures confined in the seismogenic layer and thus the definition of their rupture models include unavoidable uncertainties.

\section{Acknowledgments}

The stress tensors were calculated using a program written by J. Deng (Deng and Sykes 1997) based on the DIS3D code of S. Dunbar, which later improved (Erikson 1986) and the expressions of G. Converse. The GMT system (Wessel and Smith 1998) was used to plot the figures. The comments of T. Taymaz and an anonymous reviewer helped in the paper improvement. This work was supported by the project "Pythagoras" funded by the EPEAEK. Geophysics Department contribution 690 . 

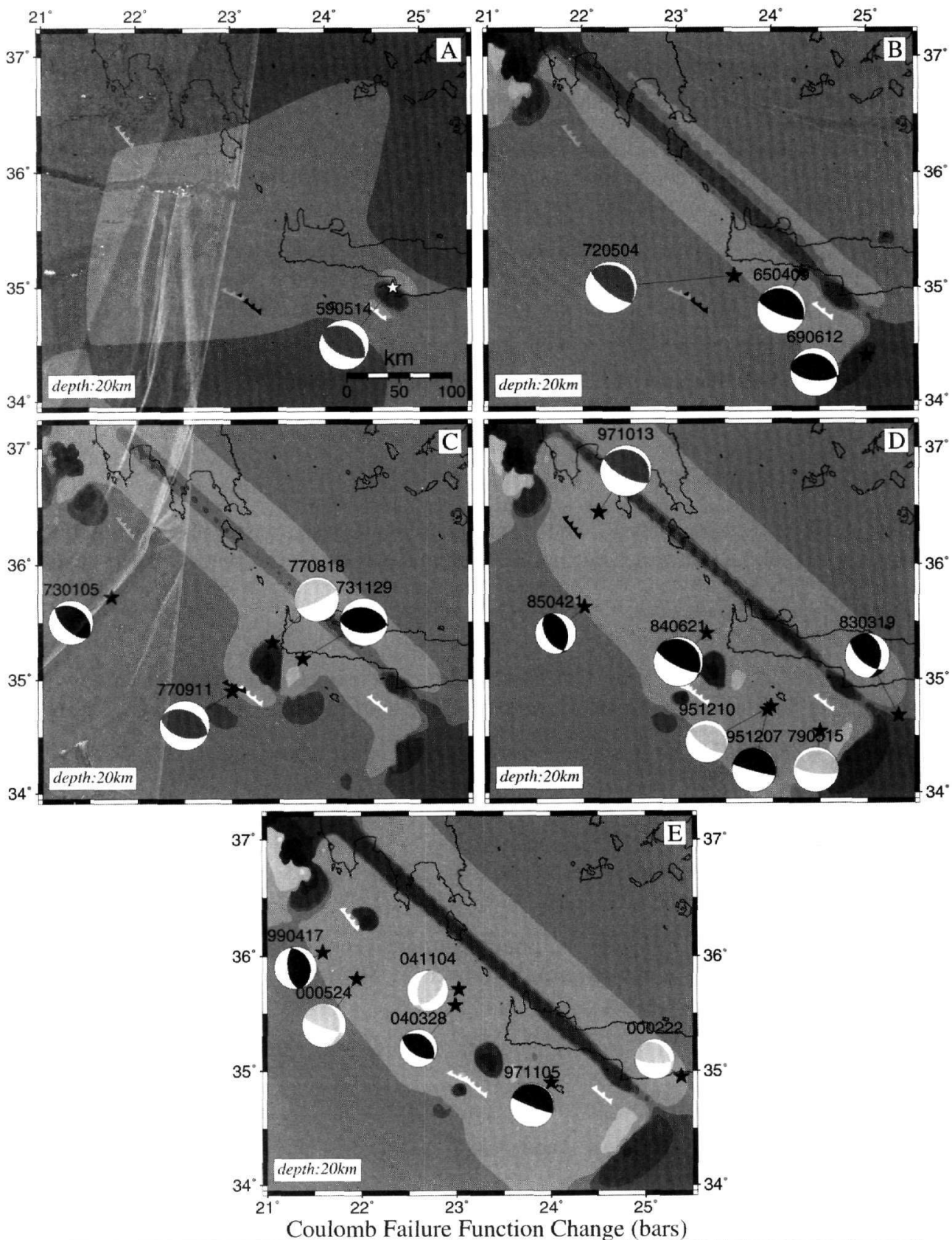

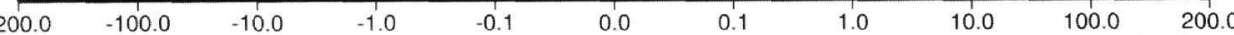

Figure 3 - Stress evolution in SW Hellenic arc since 1959. Fault plane solutions faults and epicentres are denoted as in figure 2. (A) Co-seismic Coulomb stress changes associated with

the 1959 event. (B) Stress evolution until just before the 1972 event and thrust focal mechanisms for events during 1959-1972. (C) $\triangle \mathrm{CFF}$ just before the 1977 main event along

with the fault plane solutions of events during 1972-1977. (D) Stress evolution until just before the 1997 shock with FPS of thrust earthquakes during 1977-1997. (E) State of stress in 2005 computed on the subduction interface along with thrust earthquakes that occurred in the period 1997-2005 


\section{References}

Benetatos, C., Kiratzi, A., Papazachos, C., and Karakaisis, G., 2004. Focal mechanisms of shallow and intermediate depth earthquakes along the Hellenic Arc, J. Geodyn., 37, 253-296.

Bird, P., and Kagan, Y.Y., 2004. Plate-Tectonic analysis of shallow seismicity: apparent boundary width, beta, corner magnitude, coupled lithosphere thickness, and coupling in seven tectonic settings, Bull. Seism. Soc. Am., 94, 2380-2399.

Cocard, M., Kahle, H.G., Peter, Y., Geiger, A., Veis, G., Felekis, S., Paradissis, D., and Billiris, H., 1999. New constraints on the rapid crustal motion of the Aegean region: recent results inferred from GPS measurements (1993-1998) across the Hellenic Arc, Greece, Earth Planet Sci. Lett., 172, 39-47.

Davies, R., England, P., Parsons, B., Billiris, H., Paradissis, D., and Veis, G., 1997. Geodetic strain of Greece in the interval 1982-1992, J. Geophys. Res., 102, 24,571-24,588.

Deng, J., and Sykes, L.R., 1997. Evolution of the stress field in southern California and triggering of moderate-size earthquakes: A 200-year perspective, J. Geophys. Res., 102, 9859-9886.

Dmowska, R., Rice, J., Lovinson, L., and Josell, D., 1988. Stress transfer and seismic phenomena in coupled subduction zones during the earthquake cycle, J. Geophys. Res., 98, 7869-7884.

Ergin, K., 1966. On the epicenter map of Turkey and surrounding area, Turk. Jeol. Kur. Bult., 10, 122.

Erikson, L., 1986. User's manual for DIS3D: A three-dimensional dislocation program with applications to faulting in the Earth, Masters Thesis, Stanford Univ., Stanford, Calif., 167pp.

Galanopoulos, A.G., 1967. The seismotectonic regime in Greece, Ann. Geof., 20, 109.

Govers, R., and Wortel, M. J. R., 2005. Lithosphere tearing at STEP faults: Response to edges of subduction zones, Earth Planet. Sci. Lett., 236, 505-523.

Harris, R.A., 1998. Introduction to special section: Stress triggers, stress shadows, and implications for seismic hazard, J. Geophys. Res., 103, 24,347-24,358.

Jackson, J., and McKenzie, D., 1988. The relationship between plate motions and seismic moment tensors and the rates of active deformation in the Mediterranean and Middle East, Geoph. J., 93, 45-73.

Kahle, H-G., Müller, M. V., Müller, S., Geiger, A., Danuser, G., Mueller, S., Veis, G., Billiris, H., and Paradissis, D., 1995. The strain field in northwestern Greece and the Ionian Islands: results inferred from GPS measurements, Tectonophysics, 249, 41-52.

King, G.C.P., Stein, R.S., and Lin, J., 1994. Static stress changes and triggering of earthquakes, Bull. Seism. Soc. Am., 84, 935-953.

King, G.C.P., and Cocco, M., 2001. Fault interaction by elastic stress changes: New clues from earthquake sequences, $A d v$. Geophys., 44, 1-38.

Kiratzi, A., and Langston, C., 1989. Estimation of earthquake source parameters of the May 4, 1972 event of the Hellenic arc by the inversion of waveform data, Physics Earth Planet. Inter., 57, 225-232.

Kreemer, C., and Chamot-Rooke, N., 2004. Contemporary kinematics of the southern Aegean and the Mediterranean Ridge, Geophys. J. Int., 157,1377-1392.

Le Pichon, X., Chamot-Rooke, N., Lallemant, S., Noomen, R., and Veis, G., 1995. Geodetic determination of central Greece with respect to Europe: Implications for eastern Mediterranean tectonics, J. Geophys. Res., 100, 12,675-12,690. 
Laigle, M., Sachpazi, M., and Hirn, A., 2004. Variation of seismic coupling with slab detachment and upper plate structure along the western Hellenic subduction zone, Tectonophysics, 391, $85-95$.

Lin, J., and Stein, R.S., 2004 Stress triggering in thrust and subduction earthquakes, and stress interaction between the southern San Andreas and nearby thrust and strike slip faults, J. Geophys. Res., 109, B02303, doi:10.1029/2003JB002607.

Louvari, E., 2000. A detailed Seismotectonic study of the Aegean and neighboring regions based on focal mechanisms of moderate sized earthquakes, Ph.D. Thesis, Thessaloniki, University publications, 309pp.

Lundgren, P., Giardini, D., and Russo, R.M., 1998. A geodynamic framework for eastern Mediterranean kinematics, Geoph. Res. Lett., 25, 4007-4010.

McClusky S., Balassanian, S., Barka, A., Demir, C., Ergintav, S., Georgiev, I., Gurkan, O., Hamburger, M., Hurst, K., Kahle, H., Kastens, K., Kekelidze, G., King, R., Kotzev, V., Lenk, O., Mahmoud, S., Mishin, A., Nadariya, M., Ouzounis, A., Paradissis, D., Peter, Y., Prilepin, M., Reilinger, R., Sanli, I., Seeger, H., Tealeb, A., Tosksöz, N. M., and Veis, G., 2000. Global Positioning System constraints on plate kinematics and dynamics in the eastern Mediterranean and Caucasus, J. Geophys. Res., 105, 5695-5719.

McKenzie, D. P., 1972. Active tectonics of the Mediterranean region, Geophys. J. R. astr. Soc., 30, $109-185$.

McKenzie, D.P., 1978. Active tectonics of the Alpine-Himalayan belt: the Aegean Sea and surrounding regions, Geophys. J. R. astr. Soc., 55, 217-254.

Meier, T., Rische, M., Endrun, B., Vafidis, A., and Harjes, H-P., 2004. Seismicity of the Hellenic subduction zone in the area of western and central Crete observed by temporary local seismic networks, Tectonophysics, 383, 149-169.

Papadimitriou, E. E., 1993. Focal mechanism along the convex side of the Hellenic arc, Bull. Geof. Teor. Appl., 35, 401-426.

Papadimitriou, E.E., and Karakostas, V.G., 2005. Faulting geometry and seismic coupling of the southwest part of the Hellenic subduction zone, Abstract in $33^{\text {rd }}$ IASPEI General Assembly, Santiago, Chile, 2-8 October 2005.

Papazachos, B.C., 1961. A contribution to the research on fault plane solutions of earthquakes in Greece, PhD Thesis, University of Athens, 75pp.

Papazachos, B.C., and Comninakis, P.E., 1970. Geophysical features of the Greek island arc and eastern Mediterranean ridge, Com. Ren. Des Sceances de la Conference Reunie a Madrid, $1969,16,74-75$.

Papazachos, B.C., and Papazachou, C., 1997. The earthquakes of Greece, Thessaloniki, Ziti Publications, 289pp .

Papazachos, B.C., and Papazachou, C., 2003. The earthquakes of Greece, Thessaloniki, Ziti Publications, 286pp .

Papazachos, B.C., Karakostas, V.G., Papazachos, C.B., and Skordilis, E.M., 2000. The geometry of the Wadati-Benioff zone and lithospheric kinematics in the Hellenic arc, Tectonophysics, 319, 275-300.

Papazachos, B.C., Mountrakis, D.M., Papazachos, C.B., Tranos, M.D., Karakaisis, G.F., and Savvaidis, A.S., 2001. The faults that caused the known strong earthquakes in Greece and surrounding areas during $5^{\text {th }}$ century B.C. up to present, $2^{\text {nd }}$ Conf. Earthq. Engin. and Engin. Seism., 28-30 September 2001, Thessaloniki, 1, 17-26. 
Papazachos, B.C., Scordilis, E.M., Panagiotopoulos, D.G., Papazachos, C.B., and Karakaisis, G.F., 2004. Global relations between seismic fault parameters and moment magnitude of earthquakes, $10^{\text {th }}$ Congr. Hellenic Geol. Soc., Thessaloniki, Greece, 14-17 April 2004, 539-540.

Papazachos, C.B., 1999. Seismological and GPS evidence for the Aegean-Anatolia interaction, Geoph. Res Lett., 26, 2653-2656.

Papazachos, C.B., and Kiratzi, A.A., 1996. A detailed study of the active crustal deformation in the Aegean and surrounding area, Tectonophysics, 253, 129-153.

Reilinger, R.E., McClusky, S.C., Oral, M.B., King, R.W., and Tosksöz, M.N., 1997. Global Positioning System measurements of present-day crustal movements in the Arabia-AfricaEurasia plate collision zone, J. Geophys. Res., 102, 9983-9999.

Scholz, C.H., 1982. Scaling laws for large earthquakes: Consequences for physical models, Bull. Seism. Soc. Am., 72, 1-14.

Scholz, C.H., 1990. The mechanics of earthquakes and faulting, Cambridge, Cambridge University press, $439 \mathrm{pp}$.

Scholz, C.H., 1998. Earthquakes and friction laws, Nature, 391, 37-42.

Taymaz, T., Jackson, J., and Westaway, R., 1990. Earthquake mechanics in the Helenic Trench near Crete, Geophys. J. Int., 102, 695-793.

Taymaz, T., Jackson, J. A., and McKenzie, D., 1991. Active tectonics of the North and Central Aegean Sea, Geophys. J. Int.-Oxford, 106, 433-490.

Wessel, P., and Smith, W.H.F., 1998. New, improved version of the Generic Mapping Tools Released. EOS Trans. $A G U 79,579 \mathrm{pp}$. 